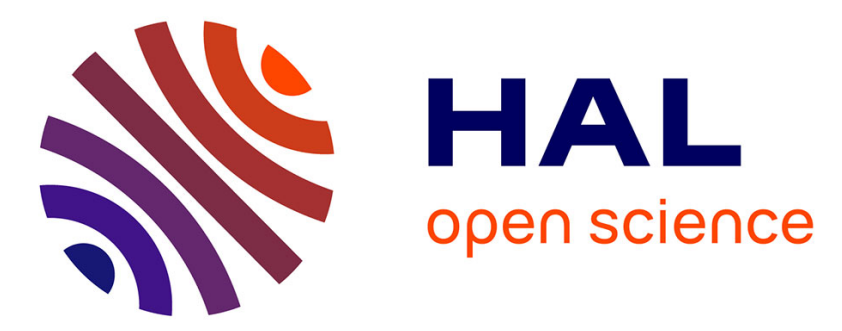

\title{
A Nested Configuration of POLCA and Generic Kanban in a High Product Mix Manufacturing System
}

Oladipupo Olaitan, Giuseppe Fragapane, Erlend Alfnes, Jan Ola Strandhagen

\section{To cite this version:}

Oladipupo Olaitan, Giuseppe Fragapane, Erlend Alfnes, Jan Ola Strandhagen. A Nested Configuration of POLCA and Generic Kanban in a High Product Mix Manufacturing System. IFIP International Conference on Advances in Production Management Systems (APMS), Sep 2017, Hamburg, Germany. pp.518-526, 10.1007/978-3-319-66923-6_61 . hal-01666186

\section{HAL Id: hal-01666186 https://hal.inria.fr/hal-01666186}

Submitted on 18 Dec 2017

HAL is a multi-disciplinary open access archive for the deposit and dissemination of scientific research documents, whether they are published or not. The documents may come from teaching and research institutions in France or abroad, or from public or private research centers.
L'archive ouverte pluridisciplinaire HAL, est destinée au dépôt et à la diffusion de documents scientifiques de niveau recherche, publiés ou non, émanant des établissements d'enseignement et de recherche français ou étrangers, des laboratoires publics ou privés.

\section{(c)(1)}

Distributed under a Creative Commons Attribution| 4.0 International License 


\title{
A Nested Configuration of POLCA and Generic Kanban in a High Product Mix Manufacturing System
}

\author{
Oladipupo Olaitan ${ }^{[0000-0002-4604-2543]}$, Giuseppe Fragapane [0000-0001-8915-509X] \\ Erlend Alfnes ${ }^{[0000-0002-9892-3916]}$ and Jan Ola Strandhagen ${ }^{[0000-0003-3741-9000]}$ \\ Norwegian University of Science and Technology (NTNU), Trondheim, Norway \\ oladipupo.a.olaitanentnu.no
}

\begin{abstract}
The work presented in this paper is part of a project aimed at streamlining and improving the process flow at a leather furniture manufacturing company. The manufacturing throughput time is highly variable, and this makes planning difficult for the assembly of components at the downstream stages. Throughput time predictability at the upstream stages where the components are manufactured would facilitate the planning of their assembly according to their expected arrival times for specific product models. Research conducted in a previous phase of the project showed that the application of the CONstant Work In Progress (CONWIP) control mechanism to regulate inventory yielded significant improvements in the throughput time's mean and variation. However, as it is the case with tighter control of inventory in manufacturing, previously unrealised problems were exposed in relation to the selection of the product model to release into the CONWIP loop. This has significant impact on the balance of the distribution of workload across the system's workstations and among the multi-skilled teams at one of the workstations.

This research implements a nested configuration of the Paired-cell Overlapping Loop Of Cards with Authorisation (POLCA) and the Generic Kanban control mechanisms to achieve a balance of the workloads. This ensures a synchronised flow of the different product mix through the entire manufacturing system. Keywords: POLCA, Generic Kanban, High-mix Manufacturing.
\end{abstract}

\section{Introduction}

The research presented in this paper is part of a project titled SØM4.0, which is aimed at streamlining and improving the process flow at a furniture manufacturing company. The manufacturing throughput time is significantly higher than the value adding time, and it is highly variable, which makes planning difficult for the downstream assembly of the components produced. In a previous phase of the project, in which CONWIP control mechanism was applied to regulate system inventory and a sequencing rule to control production at the workstations, significant improvements were achieved in the throughput time's mean and its variation $[1,2]$. However, as it is the case with tighter control of inventory in manufacturing, previously unrealised problems were exposed in relation to the selection of the product model to release into the CONWIP loop. This 
has significant impact on the balance of the distribution of workload across the system's workstations and among the operator teams at one of the workstations.

The aim of the research reported here is to implement a production control mechanism that would provide a balance of workload, both across the system's workstations and among the operator teams. This would ensure a synchronised flow of the different product mix through the system. The rest of the paper is organised as follows. In the next section (Section 2), the case study company's challenges are described in more detail. In Section 3, related production control mechanisms that have been applied to address similar challenges are reviewed and discussed. Section 4 will describe a concept for achieving workload balance through a nested configuration of control mechanisms in the case study system. Finally, Section 5 will provide insights and discussions on the nested configuration concept, by presenting its potential benefits and establishing grounds for future work to investigate the concept further.

\section{Overview of Case Study System}

The case study company is a typical example of high-mix production. The product line consists of 36 different models, most of which are offered in two or three different sizes (small, medium and large). Additionally, each model size is offered in fabric or leather material, which can also come in different variety of colours and material textures. The product differentiation starts right from the first production step, where the model design and materials are configured specifically for a product.

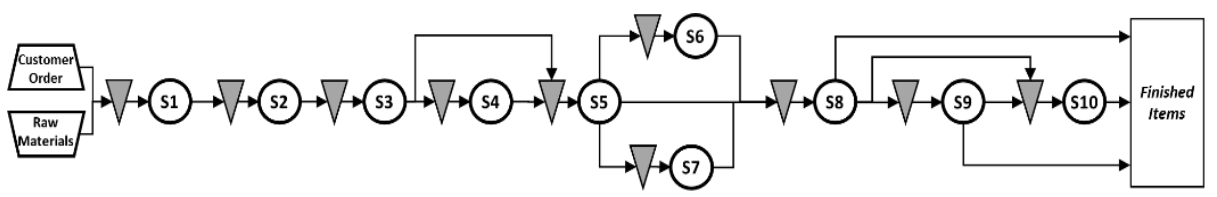

Fig. 1. Process Flow Chart

The materials for the furniture are cut in Step 1 (S1) followed by them undergoing variety of sewing operations between Steps 2 and 10 (i.e. S2 to S10). S1 is the cutting section, while S2-S10 constitute the sewing section. Semi-finished items from the sewing section undergo subsequent finishing processes, followed by assembly with foam, wood and steel components to derive the finished furniture. This work focuses on the sewing section, which has the most labour intensive and value-adding processes of the whole production. The routing possibilities through these processing steps differ from one product model to another, as shown in Fig. 1.

\subsection{Background}

The company previously applied a Push control mechanism to release items from the cutting into the sewing section, followed by applying a first in first out (FIFO) rule to sequence their processing at the workstations. Barring any capacity constraints, this should ensure that the products are completed as planned in the production order. However, the direct release of semi-finished items from the cutting section into the sewing 
section created a constant need for human intervention to re-sequence and reshuffle the in-process items. A person had to monitor the workloads at the different operator teams and redistribute waiting items to balance the workload.

To overcome the problem highlighted above, a CONWIP control was implemented in the sewing section to limit the volume of work in progress (WIP) in the section, with an intermediate buffer also created between the two sections. The lower amount of WIP, judging by Little's law [3], reduced the throughput time [1, 2]. The intermediate buffer served decoupling purposes between the flow of items out of the cutting section and their release into the sewing section. As a result, the resequencing of items became easier, as the number of items that had to be re-sequenced reduced, and the level of chaos in the sewing section reduced.

However, although the lower WIP level reduced the effort needed for reshuffling, it did not ensure a balanced workload distribution among the operator teams at S8. The release of items from the intermediate buffer into the sewing section did not consider the current workload for the operator teams, as the logic of the CONWIP mechanism does not entail this information. Prior to the implementation of the CONWIP, there were excessive items in the sewing section which ensured that the workstations and operator teams were consistently utilised. With the CONWIP, it became necessary to ensure that the limited number of items released into the sewing section consisted of a balanced distribution of workload across the workstations and among the operator teams at $\mathrm{S} 8$.

Making use of additional information, such as the capacity availability and the level of inventory downstream, can significantly improve item release decisions. And, as reported in a previous study, the release method into a system is more crucial than the sequencing or prioritisation rule at individual workstations, such that if the release rule functions well, the setting of sequencing rules for individual workstations becomes less effective or even counterproductive [4]. Hence, the aim of the current work reported here is to implement control mechanisms that will synchronise the release of items into the sewing section with the current state of the downstream workstations, particularly the operator teams at S8. This shares some of the objectives of existing production control mechanisms which are going to be discussed in the next section.

\section{Review of Literature on Related Control Mechanisms}

The card-based mechanisms that are available in literature can be categorised into unitbased or load-based, depending on if their signal card represents the physical inventory implication or the workload impact of releasing an item for processing. The original card-based mechanism was the traditional Kanban control strategy of Toyota Production System, and it was unit-based [5]. Other unit-based mechanisms are the CONWIP [6], the Generic Kanban [7], the POLCA [8] and many others. Load-based mechanisms adapted workload control concepts [4, 9] into card-based mechanisms. As such, some of the existing load-based mechanisms have retained the same control logic of previously existing unit-based mechanisms, but with load-based interpretation of their cards. Examples of such load-based mechanisms are the Constant Load (CONLOAD) [10], 
Control of Balance by Card Based Navigation (COBACABANA) [4] and Load-based POLCA [11], which can be said to be the load-based versions of the CONWIP, Generic Kanban and the POLCA respectively. The aim of these load-based implementations was to take into account that different products might have different workload impacts on a manufacturing resource, especially in high-mix systems in which the processing time requirements of the system's products vary significantly. Unit-based mechanisms, on the other hand, would not quantify the difference in the workload impacts of releasing a unit of a short processing time and a high processing time product into a system.

However, load-based mechanisms are generally less used than unit-based mechanisms, because of challenges that have to do with accurate quantification of the load impact of released item units, as well as the complexity of their software and hardware requirements for implementation and execution [12]. As evident in the COBACABANA, for which two methods of representing workload have been reported $[4,13]$, it can be difficult to find a trade-off between requiring many cards to precisely represent different product workload ranges and reducing the number of cards with the implication of a less precise load representation.

In addition to the adaptation of workload regulation concepts in card-based mechanisms, modifications have been made to their card transmission logics in order to overcome their limitations in non-repetitive, dynamic environments. This is because it is often easier to adapt a control mechanism to an environment - even if it results in some loss of effectiveness - than to adapt the environment to the mechanism [7]. Some of the common modifications are the use of generic (or centralised) control of cards as found in the Generic Kanban and the Generic POLCA, which are adaptations from the traditional Kanban and POLCA respectively. In the original control mechanisms, an item obtains the authorisation cards for processing at the workstations one at a time; while in the generic adaptations, an item must obtain all the authorisation cards it requires for its processing steps before it is released into the system. The aim is to ensure that there is available capacity at all the stages at which it is to be processed, before it is released at all into the system. Hence, once an item is released, subsequent queueing in between downstream stages is minimised, as it does not have to wait for authorisation cards. As a consequence, the system inventory level is reduced and replaced with card inventories instead. Another benefit of the generic control of authorisations cards is that it makes the control mechanisms applicable to systems with flexible routing, since each product model can dynamically select the cards for the workstations that belong in its route.

However, the global control of cards, can lead to blocking in high-mix systems in which products have different routing possibilities. Because items obtain all the cards for the workstations along their routes before being released into the system, it could become a problem for other products. If for any reason, an item becomes stuck at an upstream workstation that it does not share with other items, it will continue to hold on to downstream authorisation cards that could be directly used by other items that are processed through different upstream workstations. This could lead to starvation of the downstream workstations, if there is no card available to authorise the release of those other items. Methods, such as continuous monitoring and direct release of items to starving workstations - even if it violates their workload limits [14] - and the differentiation of indirect from direct load [15], have been proposed to avoid this problem. The 
problem has been described as premature idleness of the downstream stations, in other studies on divergent systems [13]. Another study suggests setting a proper load limit at critical points in order to avoid the problem [12].

\section{Nested Implementation of Multiple Control Mechanisms}

Based on the above, it is clear that control mechanisms, such as Generic Kanban, GPOLCA and COBACABANA, that operate generic control of cards cannot be applied in the type of highly variable routing system of this work. However, it is possible to apply elements of the Generic Kanban, in a way that takes advantage of its workloadregulating ability, to balance the workload among the operator teams at S8. It has been previously demonstrated that COBACABANA, which has a similar logic to the Generic Kanban, is effective at balancing workload across intermediate stages of a manufacturing system [12]. The Generic Kanban will be applied here to achieve a balanced workload distribution among parallel workstations, i.e. the operator teams at S8.

In a nested configuration of two control mechanisms, the POLCA will be applied across the system, while a Generic Kanban will be used to synchronise the release of items into the system to match the work rate of the operator teams. The steps involved in setting up this nested configuration are as described in the following sub-sections.

\subsection{Implementation of POLCA}

POLCA has been reported to be suitable for high-mix manufacturing environments in which the traditional Kanban control mechanism would result in the proliferation of inventory. This is because the traditional Kanban control mechanism would need to keep stage level product specific base stock for each of the products produced in the system [16]. POLCA uses its cards to signal the availability of capacity downstream and release parts for processing, unlike the traditional Kanban control mechanism which uses its cards to signal the need for the transfer of a specific part type downstream to fulfil a demand or to replenish stock. POLCA keeps inventory of cards instead of physical parts and, as a result, is able to avoid the need to keep inventory for each specific product type. The above contrasts between the two have only been made to enable the reader understand POLCA within the context of the more widely known traditional Kanban control, and to describe some of the reasons why the traditional Kanban is not being considered in this work.

The first step taken in the implementation of POLCA in the case study system is to identify the possible paired cells formation for the eight different processing routes, as shown in Table 1. As shown in the table, there are between 3 to 5 paired cells that can be formed along each of the routes.

Next, the possible paired cells across the routes are listed along with the routes to which they apply and the total number of such routes, as shown in Table 2. The aim of this information is to ensure that the paired cells are set up with adequate cards to correspond to the number of routes they serve, and the expected production volume of the products processed along the routes. This is because, as earlier discussed in Section 3, 
setting appropriate card limits at such critical points in the system is important to prevent the possibility of the system becoming blocked.

Table 1. Paired Cells for Routes

\begin{tabular}{|c|c|c|}
\hline $\begin{array}{c}\text { Paired } \\
\text { Cells }\end{array}$ & Routes Served & $\begin{array}{c}\text { Number of } \\
\text { Routes Served }\end{array}$ \\
\hline S2-S3 & All & 8 \\
\hline S3-S4 & R2 & 1 \\
\hline S3-S5 & All, except R2 & 7 \\
\hline S4-S5 & R2 & 1 \\
\hline S5-S6 & R2 & 1 \\
\hline S5-S7 & R3, R5, R8 & 3 \\
\hline S5-S8 & R1, R4, R6, R7 & 4 \\
\hline S6-S8 & R2 & 1 \\
\hline S7-S8 & R3, R5, R8 & 3 \\
\hline S8-S9 & R4, R5, R6 & 3 \\
\hline S8-S10 & R7, R8 & 2 \\
\hline S9-S10 & R6 & 1 \\
\hline
\end{tabular}

Table 2. Paired Cells and Routes Served

\begin{tabular}{|c|l|c|}
\hline Routes & Steps & $\begin{array}{c}\text { Number of } \\
\text { Paired Cells }\end{array}$ \\
\hline R1 & S2-S3-S5-S8 & 3 \\
\hline R2 & S2-S3-S4-S5-S6-S8 & 5 \\
\hline R3 & S2-S3-S5-S7-S8 & 4 \\
\hline R4 & S2-S3-S5-S8-S9 & 4 \\
\hline R5 & S2-S3-S5-S7-S8-S9 & 5 \\
\hline R6 & S2-S3-S5-S8-S9-S10 & 5 \\
\hline R7 & S2-S3-S5-S8-S10 & 4 \\
\hline R8 & S2-S3-S5-S7-S8-S10 & 5 \\
\hline
\end{tabular}

The card allowance for each paired cells can be determined using the same formula as in [17], but with the incorporation of the average lead time across the different product models that share the paired cells, as well as the expected production volume for all the product models during the planning horizon, as expressed in equation (1).

For instance, the number of cards assigned to paired cells S2-S3 will be:

$$
\text { Number of cards for paired cell } S 2-S 3=\left(L T_{S 2}+L T_{S 3}\right) \times\left(\frac{N U M_{S 2, S 3}}{D}\right)
$$

where $L T_{S 2}$ and $L T_{S 3}$ are the estimated average lead times for the two cells (workstations) over the planning period of length, $D$, and $N U M_{S 2, S 3}$ is the total number of items that go from workstation $S 2$ to $S 3$ during the same period. Here, this will be the total number across the product models that use the paired cells.

\subsection{Implementation of Generic Kanban Control}

At this point, the unbalanced workload among the operator teams at S8 has not been directly addressed, even if POLCA's balancing of workload across the system's workstations would have had indirect impact in regulating the flow of items into S8. Therefore, a Generic Kanban control mechanism is implemented to balance the workload among the operator teams. The Generic Kanban operates a global assignment of cards, which are connected to the level of WIP allowed in each team and monitored globally through centralised display boards to determine when new items can be released into the system, and the type of product model to release.

As shown in Table 3, a Generic Kanban board showing the number of free Kanbans available for each of the operator teams is displayed to support the decision on the type of product model to release from the intermediate buffer into the sewing section. This ensures that the planner releases product model types upstream in synchronisation with the work rate of the teams at S8. Therefore, the factors that have to be considered when a new item is to be released into first workstation of the sewing section (i.e. S2) are the availability of a S2-S3 POLCA card and a free Kanban for one of the operator teams 
that are capable of processing the item. From then on, the progress of an item downstream through its required workstations is controlled locally by the availability of POLCA authorisation cards for the paired cells involved, until the item reaches S8.

Table 3. Card Settings and Generic Kanban Display for Operator Teams

\begin{tabular}{|c|c|c|c|}
\hline Team & Total Number of Kanbans & Kanbans in Use & Free Kanbans \\
\hline A & 35 & 30 & 5 \\
\hline B & 26 & 26 & 0 \\
\hline C & 28 & 24 & 4 \\
\hline D & 32 & 30 & 2 \\
\hline
\end{tabular}

As earlier described, and as shown in Table 3, there are four operator teams responsible for carrying out the processing required at S8 for the different product models. Each team is capable of processing certain product models only, such that each product model would have between 2-4 teams capable of processing it. The release of an item into the paired cells that connect into S8 (i.e. S5-S8, S6-S8 and S7-S8) will be authorised by the generic Kanban connected to the group that will process the item. This should occur instantaneously, because an item must have obtained the generic Kanban before its release into the sewing section. It can be interpreted as there being four virtual loops that connect into S8 (i.e. to $8 \mathrm{~A}, 8 \mathrm{~B}, 8 \mathrm{C}$ and $8 \mathrm{D}$ ) to authorise the release of items to its operator teams. Once an item has completed processing at S8, its generic Kanban is detached and returned to the centralised Kanban board. On the other hand, the paired cells that connect out of S8 (i.e. S8-S9 and S8-S10) will operate with POLCA cards to authorise the release of items downstream.

\section{$5 \quad$ Insights, Conclusions and Future Work}

The step by step practical implementation of POLCA in a case study manufacturing system, which has variable routings and high product mix, gives a good insight to industry practitioners on how POLCA can be implemented in systems with complex product routings. It shows how paired cells can be created from the system's workstations, while reducing the complications resulting from the variety of product routings, or from the common use of the same workstations along multiple product routes. If physical distance between workstations does not make exchange and synchronisation of cards between paired workstations difficult, then POLCA should be practicable in such systems, as presented in this work.

It has been demonstrated how the benefits of different control mechanisms can be combined in one system, through a nested configuration of POLCA and the Generic Kanban control mechanisms. POLCA alone can deliver a balanced workload distribution across workstations, but combining it with the Generic Kanban control mechanism helps to achieve a balanced distribution of workload among the multi-skilled operator teams. This extends existing knowledge from previous works which have mostly focussed on balancing workload across intermediate workstations of a manufacturing system. It should be mentioned that other concepts, such as Workforce training and Staffing and Balanced product-mix release methods, have been used to achieve workload 
balance at operations involving teams. However, such static methods would only offer limited solutions to the dynamic change in product mix and routing involved in the system considered here.

The future aim of this research is to implement and optimise the nested POLCAGeneric Kanban configuration, and compare its performance against existing alternatives. Simulation modelling will be applied for this purpose, and existing techniques, such as Evolutionary algorithms and metaheuristics algorithms, which have been successfully applied in Kanban related research, will be applied in optimising its required numbers of POLCA cards and Generic Kanbans.

Acknowledgement. This research has been carried out as part of SØM4.0 project, as funded by the Norwegian Research Council's BIA programme. The authors wish to thank the project partners for facilitating this work.

\section{References}

[1] E. A. Quan Yu, Håvard Gjengstø Brekken and Mats Moen Eide, "A Simulation Enhanced VSM Approach for high-Mix Manufacturing Environment," presented at the International Workshop of Advanced Manufacturing and Automation, University of Manchester, UK, 2016.

[2] O. A. Olaitan, "Work In Process Control for a High Product Mix Manufacturing System," in The 50th CIRP Conference on Manufacturing Systems, Taichung, Taiwan., 2017.

[3] J. D. C. Little, "A Proof for the Queuing Formula: L = גW," Operations Research, vol. 9, pp. 383-387, 1961.

[4] M. J. Land, "Cobacabana (control of balance by card-based navigation): A card-based system for job shop control," International Journal of Production Economics, vol. 117, pp. 97-103, 2009.

[5] T. Ohno, "The origin of Toyota production system and kanban system," in Proceedings of the International Conference on Productivity and Quality Improvement, 1982.

[6] M. L. Spearman, D. L. Woodruff, and W. J. Hopp, "CONWIP: a pull alternative to kanban," International Journal of Production Research, vol. 28, pp. 879-894, 1990.

[7] T. M. Chang and Y. Yih, "Generic kanban systems for dynamic environments," International Journal of Production Research, vol. 32, pp. 889-902, 1994.

[8] R. Suri, "Don't push or pull-POLCA," APICS The Performance Advantage, vol. 8, pp. 32-39, 1998

[9] W. Bechte, "Load-oriented manufacturing control just-in-time production for job shops," Production Planning \& Control, vol. 5, pp. 292-307, 1994.

[10] O. Rose, "CONLOAD - a new lot release rule for semiconductor wafer fabs," in Proceedings of the 31 st conference on Winter simulation: Simulation---a bridge to the future, vol. 1, pp. 850-855, 1999.

[11] N. Vandaele, I. Van Nieuwenhuyse, D. Claerhout, and R. Cremmery, "Load-based POLCA: an integrated material control system for multiproduct, multimachine job shops," Manufacturing \& Service Operations Management, vol. 10, pp. 181-197, 2008

[12] N. Ziengs, J. Riezebos, and R. Germs, "Placement of effective work-in-progress limits in route-specific unit-based pull systems," International Journal of Production Research, vol. 50, pp. 4358-4371, 2012.

[13] M. Thürer, M. J. Land, and M. Stevenson, "Card-based workload control for job shops: Improving COBACABANA," International Journal of Production Economics, vol. 147, pp. 180-188, 2014.

[14] M. Thürer, M. Stevenson, and C. W. Protzman, "COBACABANA (Control of Balance by Card Based Navigation): An alternative to kanban in the pure flow shop?," International Journal of Production Economics, vol. 166, pp. 143-151, 2015.

[15] B. Oosterman, M. Land, and G. Gaalman, "The influence of shop characteristics on workload control," International journal of production economics, vol. 68, pp. 107-119, 2000.

[16] R. Suri and A. Krishnamurthy, "How to Plan and Implement POLCA-A Material Control System for High Variety or Custom-Engineered Products," Center for Quick Response management Technical Report, 2003.

[17] A. Krishnamurthy and R. Suri, "Planning and implementing POLCA: a card-based control system for high variety or custom engineered products," Production planning and control, vol. 20, pp. 596-610, 2009 